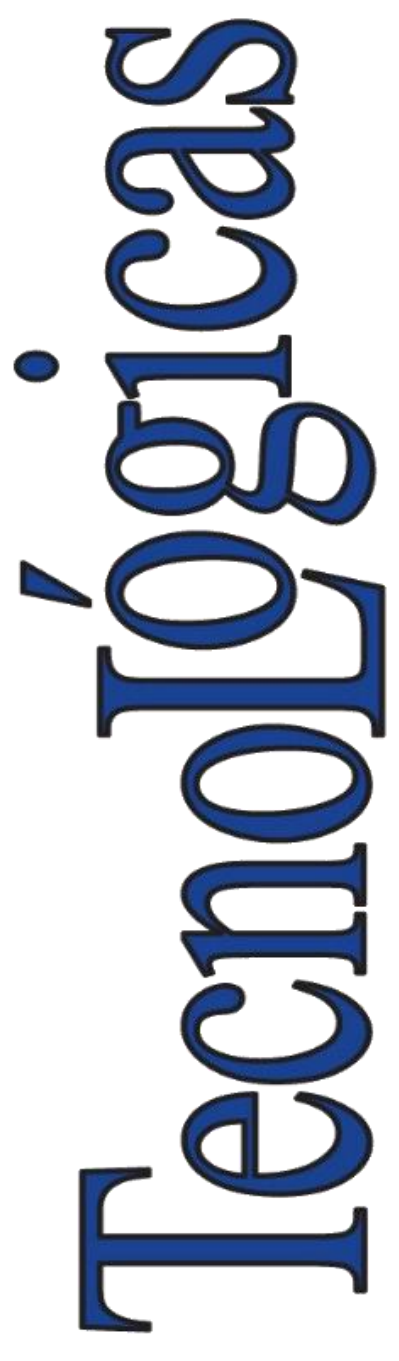

ISSN-p: 0123-7799 ISSN-e: $2256-5337$

Vol. 24, nro. 50, e1791

Recibido: 23 junio 2020 Aceptado: 11 noviembre 2020 Disponible: 30 enero 2021

CInstituto Tecnológico Metropolitano Este trabajo está licenciado bajo una Licencia Internacional Creative Commons Atribución (CC BY-NC-SA)

\section{Reference Framework for Measuring the Level of Technological Acceptance by the Elderly: A Case Study of Virtual Assistants}

\section{Marco de referencia para medir el nivel de aceptación tecnológica por parte de adultos mayores: un estudio de caso de asistentes virtuales}

\author{
(D) Manuel Bolaños ${ }^{1}$; \\ DCesar Collazos ${ }^{2}$, \\ (D)Francisco Gutiérrez ${ }^{3}$;
}

${ }^{1}$ Universidad de Nariño, Pasto-Colombia, mbolanosg@gmail.com

2Universidad del Cauca, Popayán-Colombia, ccollazo@unicauca.edu.co

${ }^{3}$ Universidad de Granada, Granada-España,

fgutierr@ugr.es

Cómo citar / How to cite

M. Bolaños; C. Collazos; F. Gutiérrez; "Reference Framework for Measuring the Level of Technological Acceptance by the Elderly: A Case Study of Virtual Assistants", TecnoLógicas, vol. 24, nro. 50, e1791, 2021. https://doi.org/10.22430/22565337.1791

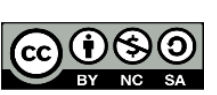




\section{Abstract}

Elderly people often have problems to use technology. As a result, the existing diversity of systems and applications adapted to this kind of users is expanding, thus facilitating the communication with their social environment, and supporting their daily activities. The aim of this study was to identify the intention of a group of older adults in Pasto, Colombia, to use smart virtual assistants and the activities in which they think these devices would be useful. Considering the participants' characteristics and in order to capture their feelings, thoughts, and experiences, we held focus groups to gather precise, clear, and simple information. The results obtained indicate that older adults can potentially use virtual assistants for their daily personal, work-related, and recreational activities. Nevertheless, motivation and technology acceptance are key aspects to ensure the usability of technological systems by this population group, and user requirements should be well defined in order to identify the characteristics and functionalities that they expect to find in such technology products. Therefore, technology developed for the elderly must meet their essential expectations in order for them to accept and adopt it in their daily lives.

\section{Keywords}

Technology Acceptance, Smart Virtual Assistant, Elderly, Playful Strategies.

\section{Resumen}

Los adultos mayores suelen presentar inconvenientes con el uso de la tecnología. Como resultado, la diversidad existente de sistemas y aplicaciones adaptadas a este tipo de usuarios se está ampliando, facilitándoles así la comunicación con su entorno social, y apoyando sus actividades diarias. Este artículo presenta los resultados de una investigación realizada para identificar la intención de un grupo de adultos mayores de utilizar asistentes virtuales inteligentes, y las actividades en las que consideran que estos dispositivos serían útiles. Para el desarrollo del estudio se trabajó con adultos mayores de la ciudad de Pasto (sur de Colombia). Teniendo en cuenta las características de los participantes y pensando en capturar sus sentimientos, pensamientos y vivencias, se utilizaron grupos focales como método para obtener información precisa, clara y sencilla. Los resultados obtenidos indican que los asistentes virtuales tienen un gran potencial para ser utilizados en las actividades personales, laborales y recreativas que diariamente realizan los adultos mayores. La motivación y la aceptación tecnológica son aspectos clave para asegurar la usabilidad de los sistemas tecnológicos por parte de los adultos mayores. Por lo tanto, es importante una buena definición de requerimientos de usuario, que permita identificar cuáles son las verdaderas características y funcionalidades que los adultos mayores esperan encontrar en estos productos. La tecnología desarrollada para adultos mayores debe cumplir con sus expectativas esenciales, para que la acepten y adopten en su vida diaria.

\section{Palabras Claves}

Aceptación de tecnología, asistente virtual inteligente, adultos mayores, estrategias lúdicas. 


\section{INTRODUCTION}

The elderly represents a growing proportion of the world population. In developed countries, it reaches $24 \%$ [1], and, in Europe, it is expected to hit $40 \%$ by 2030 [2]. According to a United Nations report, $9 \%$ of the population in 2019 was 65 and older, a percentage that is rising due to the increasing life expectancy. Thus, by 2050, this group is expected to constitute $16 \%$ of the world population [3].

Today, cultural stereotypes about aging have led people to experience some fear of this stage of the natural human lifecycle, which can cause episodes of depression and even social and emotional isolation [4]. Therefore, understanding how the elderly use technology products, as well as the characteristics of their environments, can help to respond with innovative design and face the challenges of an aging population [5]. In consequence, rapidly advancing technology can be a tool to create user-friendly devices and applications that benefit the lifestyle of the elderly [6].

The increase in the elderly population has led to the development of appropriate solutions for this kind of users, and, although there are some ICT-based services designed to help and improve their quality of life, the relationship between services and ease of use is not strong, which reduces their usefulness. Technology products developed for the elderly must be accessible, attractive, and easy to use.

Most software development initiatives target users who have technology skills, leaving aside a great potential for other possible users. Older adults are motivated to learn, keep their brains active, and are able to interact in the digital society in which they are immersed [7].

When applications are developed or systems are built for older people, they generally aim to be robust, stable, and reliable; however, these requirements are not necessarily those of the elderly for their acceptance and use. Implementing characteristics such as bigger font sizes or inverted colors in user interfaces does not guarantee usability and acceptability.

Likewise, such users should perceive valuable services and usefulness because the simple offer of services does not guarantee that [8].

Technology products developed for the elderly must meet the essential expectations of their users to be accepted and adopted in their daily lives. Besides, the elderly should not feel intimidated by the complexity of installing and using applications, as they may be discouraged from using them [2].

A study to determine the intention of the elderly to use technology can determine the elements and characteristics they expect to find when they interact with technological devices and systems. This should be reflected in the future design and implementation of solutions for this kind of users; in this particular case, in the design of playful experiences supported by smart virtual assistants. The latter are technological tools created to facilitate different processes and daily-life activities, and they can generate an experience closer to the interaction with people in a social environment.

Due to their high level of accessibility for the elderly, smart virtual assistants favor a natural interaction and reduce the technological gap thanks to their friendly interaction paradigms, which are close to how they carry out their daily activities. Besides, due to their technological characteristics, smart virtual assistants allow the generation of collaborative environments within the environment where the elderly are. Therefore, playful strategies based on smart virtual assistants can be ubiquitous, transparent, and comfortable to interact with [9].

Virtual assistants in the market, such as Echo Dot Alexa, Siri, Google Assistant, Cortana, and Bixby, have greatly helped to integrate and keep the elderly active, in addition to facilitating their daily tasks [10]. 
Virtual assistants offer different functionalities to users, and they have useful features that allow them to be easily and quickly integrated into so-called smart homes. For instance, they can turn the lights on and off, adjust the temperature, turn on or interact with other devices, search for information online, read the weather forecast, set reminders, play music, make restaurant reservations, manage emails, and make calls, among other things [11].

Thus, smart virtual assistants have gradually become indispensable elements for all sorts of people to do their daily activities.

Some of the current solutions developed for the care of the elderly integrate the preferences and functionalities that these users require, which should help, in some way, to guarantee a high degree of technology acceptance. However, there is no evidence in the literature that clearly indicates the methodologies, techniques, and tools that should be used for their design.

The following are some experiences that we can use to learn about the singularities of the design and implementation of technology for the elderly.

SAFER is a ubiquitous and intelligent platform for the care of the elderly. It aims to provide a set of intelligent services that contribute to improving their quality of life and autonomy, as well as increasing social interaction between them, by taking advantage of technological advances in terms of benefits and information security to provide comprehensive care [12].

Its architecture consists of four interactive layers (see Figure 1), communication and detection, cloud computing, knowledge management, and intelligent assistance application.

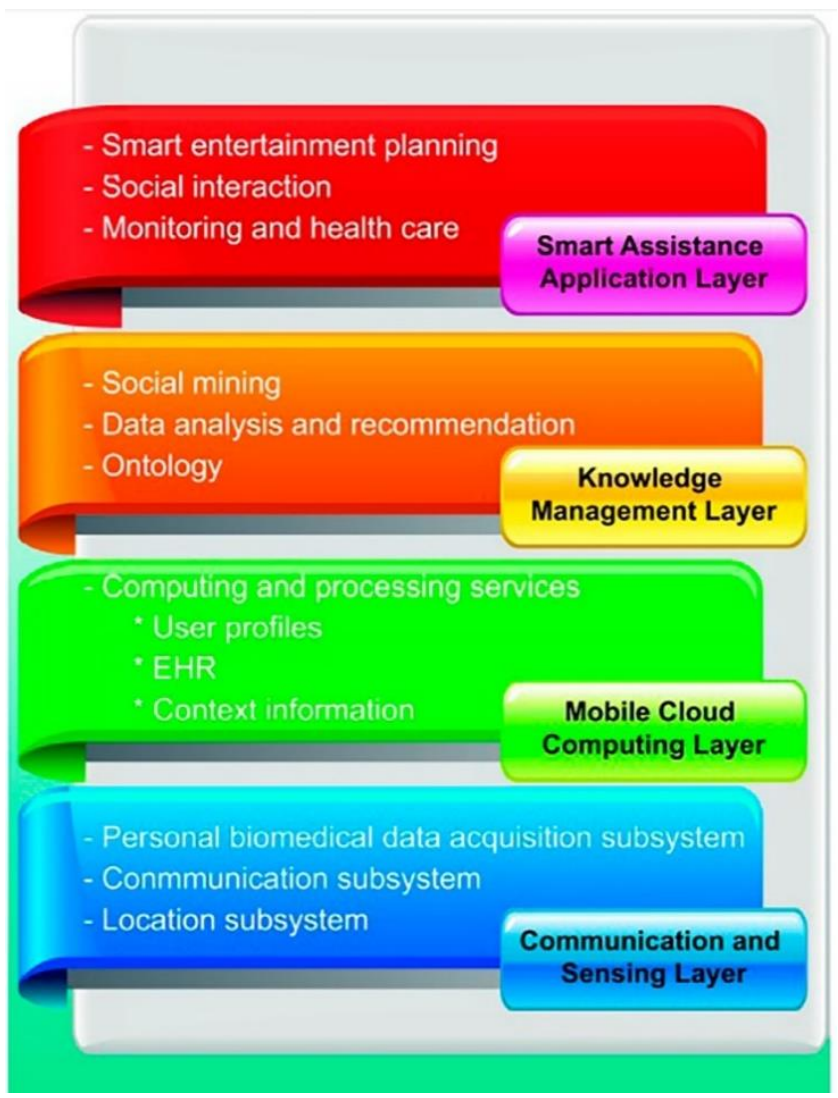

Figure 1. Layers of SAFER platform. Source: [12]. 
It also has four subsystems. The first one of them extracts information from the elderly and transmits it in real-time, while the second one coordinates the emergencies that are generated, involving agents that reorganize the monitoring of vital signs, such as hospitals and physicians. The third subsystem performs the storage, processing, and intelligence of the platform, and the last one is in charge of providing remote medicine services and, at the same time, it constitutes the interface with the user [12].

An application for mobile devices developed to promote the social interaction of the elderly is presented in [13]. The application stores each of its users' preferences and compares the content with the events that take place in the city. Afterward, it sends the elderly recommendations of where they can go and with what group of other older adults. The main objective of the application is to increase the social interaction of people over 60 based on the premise that it is very common for them to feel alone.

InTouch is an application that allows a two-way asynchronous communication and aims to connect the elderly with friends and relatives using an iterative user-centered design. Its creators used a case study approach to better understand the factors that affect the experience of elderly with mild cognitive impairment while using the app (see Figure 2). They analyzed and compared their results to obtain patterns of use and thus be able to address the difficulties in a better way for the elderly in order to generate positive social experiences with the use of InTouch [14].
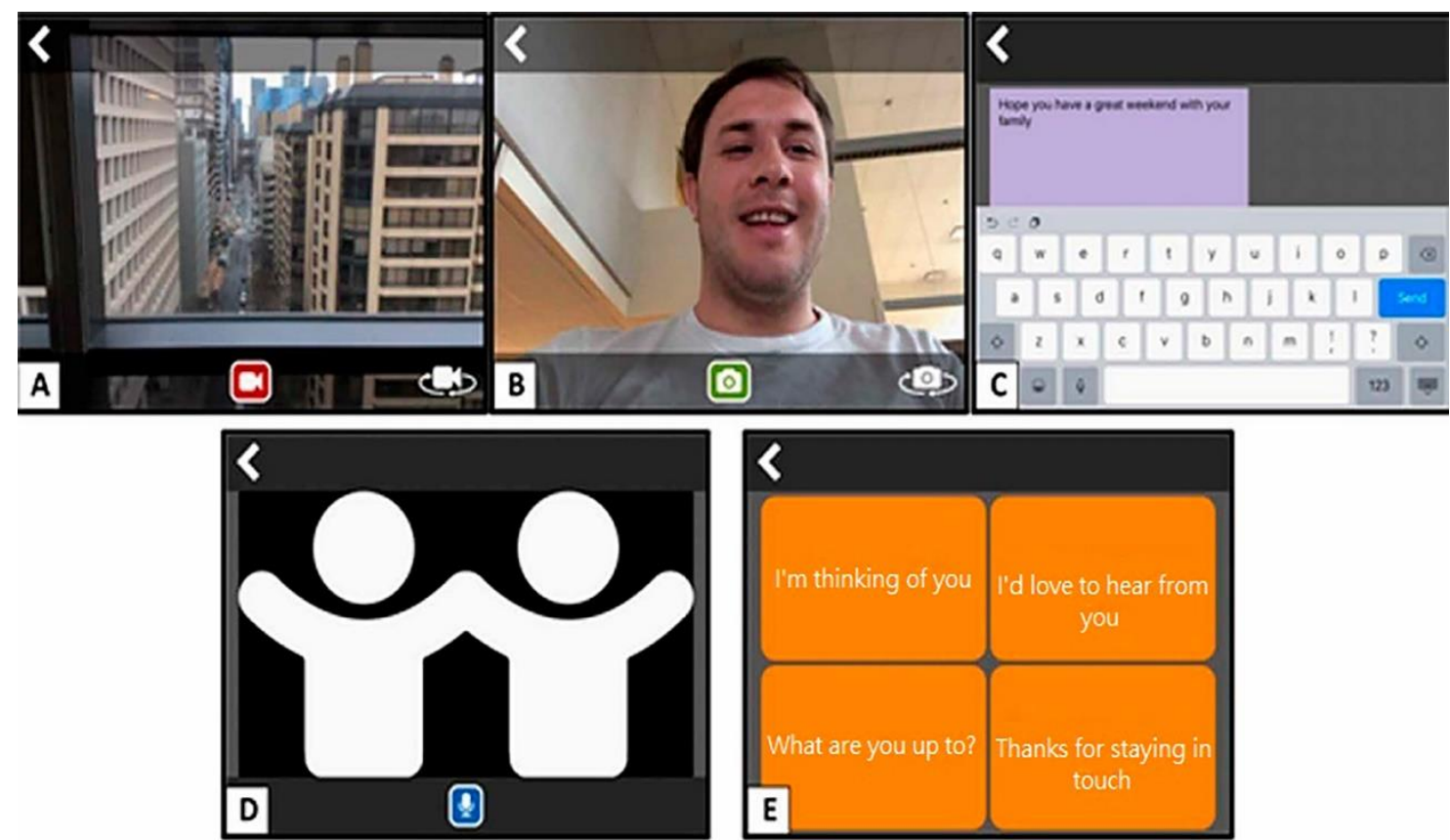

Figure 2. Message Composition screens of the InTouch application: (a) video, (b) photo, (c) custom text, (d) audio, and (e) preset ("Wave"). They are used to create content and share it with the user's preselected contact Source: [14].

In [2], the authors make an important contribution to the field of user-centered exoskeleton design and prospective approaches to study the technological acceptance of such devices by older adults. Their paper traces the evolution of technology acceptance models (TAM) regarding technology applications for the elderly. They discuss the importance of assistive technology (AT) models to assess the suitability of a device for a person with a 
disability. A clear result of their study was that empirical search should be conducted on the use and perceptions of older adults of exoskeleton technologies in order to expand the understanding of the theoretical and design factors that affect their adoption.

SocialBike is a prototype that uses the Ambient Assisted Living (AAL) paradigm, is based on virtual reality, and it is developed based on an already clinically tested system. It aims to improve the clinical results of frail elderly. It proposes a dual-task training program, in which users must do a bike-like exercise while recognizing the animals or objects that appear on the road. This helps to prevent falls, which is one of the most critical problems in the elderly (see Figure 3). It also offers the possibility of interacting with other users and reducing the risk of social isolation by choosing a multiplayer mode in which they can train according to each user's capabilities. At the same time, the elderly can talk by chat during the exercise. The application showed good usability. Nevertheless, the real costs of the complete solution must be taken into account through an adequate business model that implements a rental mechanism for the provision of rehabilitation equipment to the home of each end user [15].

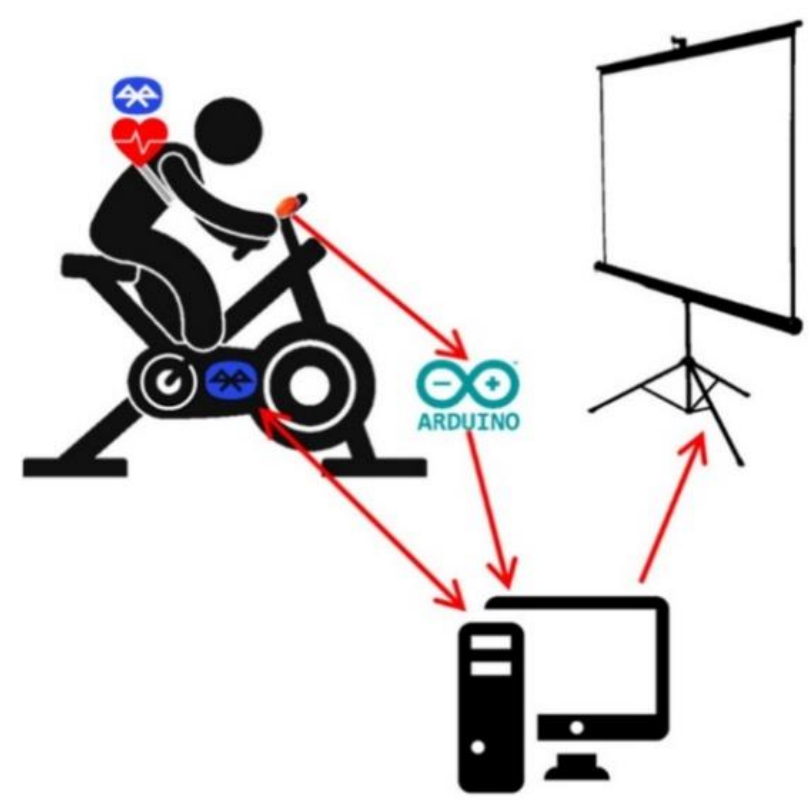

Figure 3. A social virtual reality-based application for the physical and cognitive training of the elderly at home. Source: [15].

Another study analyzed the needs of disabled users and the mobile software adaptations required to satisfy them. It introduced a methodological approach to design and develop webbased inventories, making the search for and the selection of assistive technology (AT) apps simpler and more efficient. Furthermore, such methodology aimed to have a consistent and well-documented presentation of each free mobile AT application (see Figure 4). Finally, it presents the mATHENA repository, which has been designed following the suggested methodology to create inventories of assistive technology (AT) applications and includes 420 carefully selected AT applications that could potentially benefit the disabled and the elderly [16]. 


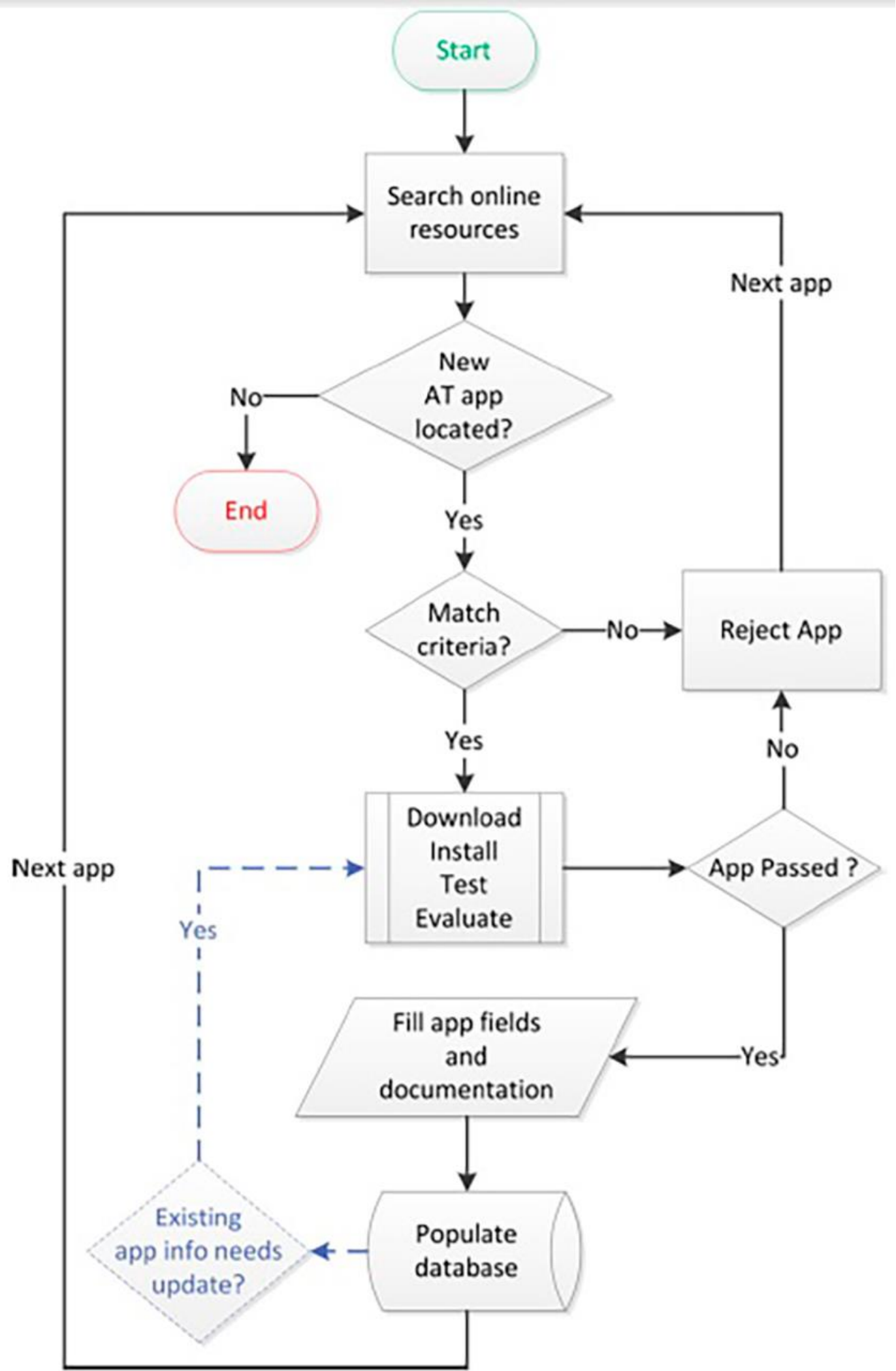

Figure. 4. Flowchart of the AT app selection procedure. Source: [16]. 


\section{METHOD}

Although models such as the Technology Acceptance Model (TAM) [17] or the Senior Technology Acceptance Model (STAM) [18] define a set of elements and variables to take into account to measure the level of acceptance of a technology, an analysis of why the group of older adults studied here do not use technology has not been conducted. Furthermore, the way technology should be changed should be identified so that older people use it.

Taking into account the above, the objectives of this paper were (1) to study the intention of the elderly to use smart virtual assistants and (2) to identify the characteristics these users would like to find when they interact with this kind of devices. The information thus obtained will serve to design playful experiences supported by virtual assistants.

For the development of the study, there was a group of 24 older adults from Pasto city (in southern Colombia), who have prioritized certain daily activities depending on their roles, so they were integrated into the following four groups:

- A first group made up of elderly who remain in contact through some type of association.

- Another group that meets periodically for physical and sports activities.

- A third group made up of professionals who are and were active in university teaching full and emeritus professors.

Considering these groups of participants and to capture their feelings, thoughts, and lives, we used focus groups as a tool to obtain accurate, clear, and simple information [19]. For that purpose, we prepared a survey and a semi-structured interview to gather basic information about each of the participants and their expectations after interacting with an intelligent virtual assistant. The goal was to identify preferences and elements to take into account in the future design and development of playful experiences supported by this technology in order to ensure they will have a high level of acceptance by the elderly.

Each group was introduced to the concept of smart virtual assistants, their purpose, and how they work. Echo Dot ${ }^{\circledR}$ by Amazon was selected due to its ease of use and because it allows the generation of playful environments by having functionalities in which several older adults can simultaneously interact in a pleasant activity for them. As a result, user can follow professional guidelines and the device can produce and response.

Each focus group was composed of six people who could directly observe the operation of the device. This activity allowed them to have an unprecedented experience with technology. Now they did it with help, but if we address the aging of this small group of Colombians, and it is compared with population groups in Latin American countries such as Costa Rica, Mexico and Chile, with respect to functional dependence, that is, the performance of the elderly in basic activities of daily life, increasingly depend on another person [20]. In Latin America, more than eight million elderly cannot independently do at least one basic activity of daily life such as bathing, preparing food, or eating, [20]. Furthermore, as expressed in the group interviews, many participants in this study are not able to search for information on their cell phone or make a video call. Functional dependence in the region affects a large percentage of the elderly, reaching $12 \%$ in people aged 60 years and over, and almost $27 \%$ in people aged 80 or over [21]. According to the statistics, the elderly in several Latin American countries present the same general characteristics of older Colombian adults. In general, they have someone do at least one of their activities [20]; hence, personal success is linked to the success of others, generating positive interdependencies and permanent social interaction [22]. In addition, they can work in collaborative and ubiquitous environments because they can acquire communication, cooperation, and teamwork skills, which result in the integration of 
the participants [22], who can interact without time and space restrictions and take advantage of the processing and communication capabilities offered by the device [23].

Later in this study, the elderly interacted with other functionalities of the assistant, such as managing their schedule, calendars, scheduling reminders, interacting with other devices, making shopping lists, and entertainment. After the participants interacted with the device, they were invited to complete a survey that included basic data and their interest in using a virtual assistant. The survey was divided into four main aspects (company and communication with family and friends, reminders, help with housework, and help with medical procedures).

At this point, interesting topics can be addressed to contribute to the understanding of the current situation of older adults and their relationship with doing basic daily activities. The National Administrative Department of Statistics (DANE in Spanish) estimates that there are a total of 48,258,494 people in Colombia, $9.1 \%$ of which are adults over 65 years of age [24]. According to Inter-American Development Bank (IDB) data, in 2015, in Colombia, 10.8 $\%$ of the older people were in the 60 to 80 age range; and the corresponding projection indicates that this share will exceed $18 \%$ in 2030 [20]. Therefore, the participants in this study represent a growing population group that will need increasingly more care. Also, the social isolation they are exposed to [25] is an objective indicator that can be measured using variables related to membership and participation in groups or associations. The four focus groups describe above are in some way linked to group activities in various periods of time, in this sense, the following aspect related to the use of technology, support, the benefits of virtual assistants in the basic activities of daily life, they are not far from a phenomenon that draws attention due to its worldwide trend: loneliness, referred to by this term in the DANE document [25], in which it is analytically implicating in three aspects mentioned there, singleperson households, the participation of households in social instances and supportive social networks, and loneliness in times of pandemic.

Once the survey was completed, an interview was conducted with each one of the groups to address three main points: (1) "How comfortable did you feel when you interacted with the virtual assistant?" (2) "How would you rate your interaction with the device?" and (3) "Describe your experience, highlighting the positive aspects and the aspects that you consider should be improved." The methodology we used revealed the intentions of most of this group of older adults to use intelligent virtual assistants.

\section{RESULTS AND DISCUSSION}

The information recorded in the surveys and collected in the interviews shows the perception of the participating older adults of the acceptance of virtual assistants and their interest in using them to carry out different activities of their daily life.

The basic information provided by the 24 participants is summarized in Table 1 . From the point of view of functional dependence, it can be observed that all the participants show selfsufficiency to carry out their daily activities. However, the data also indicate that $45.83 \%$ of them have at least one disease and are taking medications, which opens up the picture for virtual assistant functionalities, such as reminding names, dosages, and times to take medications, as well as scheduling medical appointments. These are activities that they can learn how to program with the help of a close relative. According to the above, all participants show self-sufficiency to do their daily activities. Hence, they did not need any special type of help or activity to participate in the following stages of this study. 
Table 1. General information about the participants in this study. Source: Created by the authors.

\begin{tabular}{cccccccc}
\hline Gender & $\begin{array}{c}\text { Self- } \\
\text { sufficient }\end{array}$ & $\begin{array}{c}\text { Has a } \\
\text { disease }\end{array}$ & $\begin{array}{c}\text { Requires } \\
\text { medication }\end{array}$ & $\begin{array}{c}\text { Lives } \\
\text { alone }\end{array}$ & Income & Works & Age \\
\hline Male & Yes & Yes & Yes & No & Yes & No & 83 \\
Female & Yes & No & No & No & Yes & Yes & 72 \\
Male & Yes & No & No & No & Yes & No & 85 \\
Female & Yes & No & No & No & Yes & Yes & 72 \\
Male & Yes & Yes & Yes & No & Yes & No & 85 \\
Male & Yes & No & No & No & Yes & No & 83 \\
Female & Yes & Yes & Yes & No & Yes & Yes & 75 \\
Female & Yes & Yes & Yes & No & Yes & Yes & 62 \\
Female & Yes & Yes & Yes & No & Yes & No & 69 \\
Male & Yes & Yes & Yes & No & Yes & Yes & 61 \\
Female & Yes & Yes & Yes & No & Yes & No & 70 \\
Female & Yes & Yes & Yes & No & Yes & No & 78 \\
Male & Yes & No & No & No & Yes & Yes & 74 \\
Male & Yes & No & No & No & Yes & Yes & 63 \\
Male & Yes & No & No & No & Yes & Yes & 64 \\
Male & Yes & No & No & No & Yes & Yes & 62 \\
Male & Yes & No & No & No & Yes & Yes & 68 \\
Male & Yes & No & No & No & Yes & Yes & 61 \\
Male & Yes & Yes & Yes & No & No & No & 68 \\
Female & Yes & Yes & Yes & No & No & No & 71 \\
Male & Yes & Yes & Yes & No & Yes & No & 81 \\
Female & Yes & No & No & No & No & No & 70 \\
Female & Yes & No & No & No & No & No & 72 \\
Male & Yes & No & No & No & Yes & Yes & 68 \\
\hline
\end{tabular}

All the participants live with other people, i.e., close relatives who keep them company and help them. This information is important because those companions can offer support to fulfill the fundamental objectives of the recreational experiences that we want to design: to promote and generate collaborative environments. As a result, the elderly can interact with the device in group activities with greater confidence, which also allows them to socialize and receive support to use technology if necessaryFrom the economic standpoint, $83.33 \%$ of the participants receive an income and $50 \%$ are currently working, which allows them to have a certain level of freedom and autonomy in making decisions regarding investing in acquiring technology.

Table 2 details the preferences of the participants regarding the activities for which they would use a virtual assistant, and Table 3 presents the total values and the percentages of their preferences. It should be noted that, in the survey, the participants were asked what activities they can carry out with help. In fact, laundry and food preparation were noticeable for some of the men, but very few. Their responses show that most participants, at the moment of the interview, did their daily activities without any help, but they also acknowledged the benefits of virtual assistants for other activities. For instance, participants could go to the pharmacy of their health insurance company to pick up their medications, and a virtual assistant can issue a reminder message of the dosage and time of the medication intake. Nevertheless, only the person can perform the action. 
Table 2. Preferences regarding activities that virtual assistants could be used for. Source: Created by the authors.

\begin{tabular}{|c|c|c|c|c|}
\hline & $\begin{array}{l}\text { Company and } \\
\text { communication }\end{array}$ & Reminders & Housework & Medications \\
\hline \multirow{4}{*}{ Group 1} & $\mathrm{X}$ & & & $\mathrm{X}$ \\
\hline & $\mathrm{X}$ & $\mathrm{X}$ & $\mathrm{X}$ & $\mathrm{X}$ \\
\hline & & & & $\mathrm{X}$ \\
\hline & $\mathrm{X}$ & & $\mathrm{X}$ & $\mathrm{X}$ \\
\hline \multirow{6}{*}{ Group 2} & $\mathrm{X}$ & $\mathrm{X}$ & $\mathrm{X}$ & $\mathrm{X}$ \\
\hline & $\mathrm{X}$ & $\mathrm{X}$ & $\mathrm{X}$ & $\mathrm{X}$ \\
\hline & $\mathrm{X}$ & & $\mathrm{X}$ & \\
\hline & $\mathrm{X}$ & & $\mathrm{X}$ & $\mathrm{X}$ \\
\hline & $\mathrm{X}$ & $\mathrm{X}$ & $\mathrm{X}$ & $\mathrm{X}$ \\
\hline & $\mathrm{X}$ & $\mathrm{X}$ & $\mathrm{X}$ & $\mathrm{X}$ \\
\hline \multirow{4}{*}{ Group 3} & $\mathrm{X}$ & & & \\
\hline & $\mathrm{X}$ & & $\mathrm{X}$ & $\mathrm{X}$ \\
\hline & & & & $\mathrm{X}$ \\
\hline & $\mathrm{X}$ & & & \\
\hline \multirow{5}{*}{ Group 4} & & $\mathrm{X}$ & $\mathrm{X}$ & \\
\hline & & & $\mathrm{X}$ & \\
\hline & $\mathrm{X}$ & $\mathrm{X}$ & & $\mathrm{X}$ \\
\hline & $\mathrm{X}$ & & & \\
\hline & $\mathrm{X}$ & & & \\
\hline
\end{tabular}

Table 3. Consolidated preferences regarding the use of virtual assistants Source: Created by the authors.

\begin{tabular}{ccccc} 
& \multicolumn{4}{c}{ Company and } \\
& communication & Reminders & Housework & Medications \\
\hline Group 1 & 3 & 1 & 2 & 4 \\
Group 2 & 6 & 4 & 6 & 5 \\
Group 3 & 3 & 0 & 1 & 2 \\
Group 4 & 3 & 2 & 2 & 1 \\
\hline & $62.50 \%$ & $29.16 \%$ & $45.83 \%$ & $50.00 \%$ \\
\hline
\end{tabular}

Importantly, $79.16 \%$ of the participants consider that they would use a virtual assistant for at least one of the four listed activities. This is a significant percentage if one takes into account that all of them are self-sufficient in terms of performing their daily tasks, and their preference is not associated with an imperative need. Furthermore, $50 \%$ of them are currently working, which suggests that they could consider, in the near future, using virtual assistants to organize their work.

The fact that $62.50 \%$ of the participants would use a virtual assistant for company and communication allows us to infer that using social networks, for example, is part of their daily activities. They prioritize it because they need socialize and avoid social isolation. Half of the participants would use virtual assistants to help with medical procedures, using some of their functionalities such as creating agendas and to-do lists. 
Housework, with a 45.83preference, shows that nearly half of the participants find an opportunity in virtual assistants to control their household chores. It should be noted that these self-imposed schedules are necessary for their well-being.

Reminders, with $29.16 \%$, have the lowest percentage, which is a reflection of the fact that the participants consider themselves self-sufficient in terms of doing their daily activities, and they feel they can fully use their cognitive and memory skills. Two participants in the group who live at a nursing home said they would use virtual assistants for reminders and housework. This answer, in the setting of a nursing home, is different from those of the other focus groups we interviewed. Of course, a device that offers support to an elderly adult has a great responsibility. Sadly, the communication of patients in nursing homes with their relatives outside is limited, and medical procedures are part of the itinerary of the health care staff, not of the elderly.

Their answers indicate that $79.16 \%$ of the participants would use a virtual assistant for at least one of the four proposed activities. All the participants live with other people, i.e., close relatives who provide support and help; $45.83 \%$ have at least one disease and are taking medications; and $62.5 \%$ would use a virtual assistant for company and communication, which allows us to infer that they need to socialize and avoid social isolation. This experience with focus groups confirms that virtual assistants hold potential to be used in the daily activities of older adults, whether personal or work-related.

In Colombia, $4.3 \%$ of older adults suffer from a progressive reduction of physical and mental capacities, which may imply an increase in the development of chronic diseases [20].

In the near future, family support will not be enough because households have fewer and fewer members; in addition, women do the household chores but also go to work. These realities are changing people's lifestyles, and technology can be used for some activities that reduce social isolation.

The information we obtained shows that, before developing playful strategies supported by virtual assistants, further research should be conducted to identify the specific activities for which older adults consider they can use virtual assistants.

The most important positive aspects and the recommendations mentioned by the participants after their interaction with the virtual assistant are shown in Table 4. It also includes some research notes that refer to important aspects that must be considered in the design of the playful experiences to be developed.

The results obtained from the responses to the surveys and the interview with each group were satisfactory in terms of the acceptance of the virtual assistant and its functionalities. Likewise, important information was obtained about certain characteristics that the participants would like to see implemented in this type of devices to improve their level of acceptance and adaptability.

The participants clearly understand the advantages of interacting with the virtual assistant discussed in the interviews and the value of having an assistive device. This experience had a positive influence on participating older adults. Furthermore, the computer applications contained in the device, which adults discover in practice, can be immediately used to fulfill their needs, i.e., setting alarms, creating a work schedule, reminding to pay bills, making calculations, and scheduling a walk, among others. Finally, the fact that the virtual assistant can be used in the language spoken by the elderly, in this case Spanish, makes them feel comfortable and safe to interact with the technology.

The comments of the participants (see Figure 5) describe their perceptions before and after their experience with the virtual assistant, which were defined by their tastes and the range of functions offered by the device. 
Table 4. Positive aspects and recommendations. Source: Created by the authors.

\begin{tabular}{|c|c|c|c|}
\hline & Positive aspects & Recommendations & Research notes \\
\hline Group 1 & $\begin{array}{l}\text { This device can greatly help the } \\
\text { elderly to remember things to } \\
\text { do, such as medical } \\
\text { appointments and meetings. }\end{array}$ & $\begin{array}{l}\text { The device should be wireless for } \\
\text { portability. } \\
\text { The device should be smaller and } \\
\text { lighter. }\end{array}$ & $\begin{array}{l}\text { Identify strategies to improve } \\
\text { reminder functionalities. } \\
\text { Consider the design and } \\
\text { portability of the device. }\end{array}$ \\
\hline Group 2 & $\begin{array}{l}\text { Alexa is very useful, especially } \\
\text { to remind the elderly about } \\
\text { things since we are very prone } \\
\text { to forgetting, and it also serves } \\
\text { as a company. }\end{array}$ & $\begin{array}{l}\text { The device is very useful when } \\
\text { you are at home, but it would be } \\
\text { much more useful if it were } \\
\text { portable, not necessarily } \\
\text { connected to a power outlet. } \\
\text { It would be nice to be able to } \\
\text { personalize it and make it more } \\
\text { friendly, including a more } \\
\text { familiar voice. }\end{array}$ & $\begin{array}{l}\text { Consider what should be improved } \\
\text { in functionalities related to } \\
\text { reminders and tasks related to } \\
\text { games, trivia, and entertainment. }\end{array}$ \\
\hline Group 3 & $\begin{array}{l}\text { It is very useful for people who } \\
\text { have memory problems, as it } \\
\text { can remind them of different } \\
\text { things like taking medicine or } \\
\text { just because they need } \\
\text { company to keep their cognitive } \\
\text { abilities active. }\end{array}$ & $\begin{array}{l}\text { It would be important if the } \\
\text { device could be carried } \\
\text { everywhere because the elderly } \\
\text { do not stay at home all the time. }\end{array}$ & $\begin{array}{l}\text { Identify strategies that help to } \\
\text { maintain cognitive skills active. } \\
\text { Improve functionalities related to } \\
\text { reminders. } \\
\text { Consider the design features of the } \\
\text { device. }\end{array}$ \\
\hline Group 4 & $\begin{array}{l}\text { It would be very useful to } \\
\text { remember things like where a } \\
\text { receipt was left or when bills } \\
\text { should be paid. It serves as a } \\
\text { company and makes some } \\
\text { activities easier. }\end{array}$ & \begin{tabular}{|l|} 
It must always be connected to a \\
power outlet. It would be nice if it \\
had a rechargeable battery to be \\
able to carry it to activities like \\
exercise. It could be a decoration \\
if it had another shape.
\end{tabular} & $\begin{array}{l}\text { Consider allowing access to web } \\
\text { apps related to the provision of } \\
\text { services. } \\
\text { Consider the design features and } \\
\text { portability of the device. }\end{array}$ \\
\hline
\end{tabular}

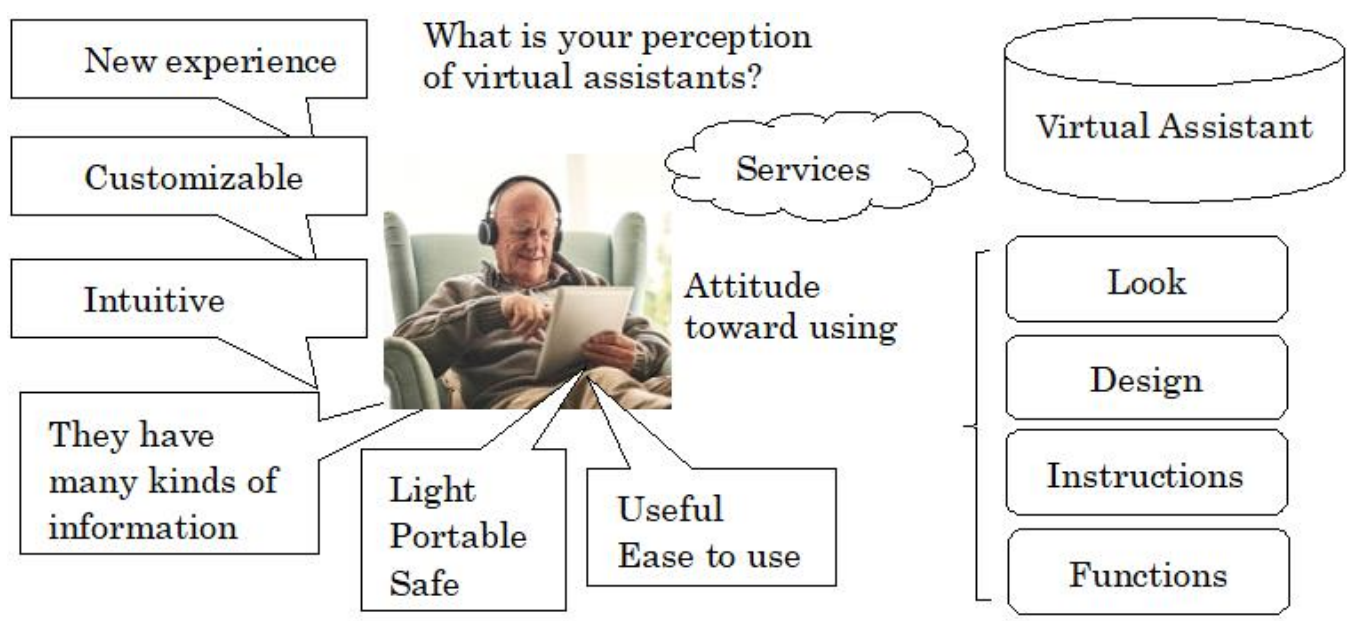

Figure 5. Participants' perceptions of virtual assistants after the experience. Source: Created by the authors.

A descriptive analysis of the figure reveals that devices must conform to the physical characteristics required by users. Thus, it can be inferred that users have prior knowledge, are interacting with information, and have developed a habit of use. The ergonomics of virtual assistants promotes their incorporation into the daily routines of the elderly, who acquire habits little by little. As a result, their real-life activities can be complemented with virtual ones in terms of efficiency and effectiveness. 


\section{CONCLUSIONS}

The recommendations made by the elderly who participated in this study are the basis for proposing and designing playful strategies supported by intelligent virtual assistants that have the characteristics that this kind of users would like to find. Technology acceptance studies aimed specifically at the elderly should be conducted so that each of the necessary factors can be precisely identified and they perceive valuable services and usefulness in technological products, which can guarantee their usability and acceptability.

The elderly can use smart virtual assistants for work, entertainment, and even healthrelated activities thanks to their voice user interface, ease of use, and level of acceptance among users.

Considering the particularities of older adults, new strategies should be developed to allow technology developers to understand and respond to their specific requirements and facilitate the use and acceptance of this technology. Technology has become a fundamental pillar in different contexts of the daily life of the elderly; as a result, specific product lines that meet each the needs of this large and important group of users should be identified.

In order to conduct studies of technological acceptance by the elderly, each of the existing technology acceptance models should be analyzed to determine if any of them includes the necessary elements to ensure that its application will bring clear and accurate results. If that is not the case, a new technology acceptance model should be defined specifically for older adults.

\section{ACKNOWLEDGEMENTS}

The study developed did not have funding, but the authors are especially grateful to the elderly participants from Pasto (Colombia) and the research groups Galeras.Net at the University of Nariño, IDIS at the University of Cauca, and GEDES of the University of Granada for their support. They also appreciate the support of the PERGAMEX-ACTIVE project. Designing Pervasive Play Experiences Using Virtual Assistants to Promote Active Aging in the Digital Home Environment. Ref. RTI2018-096986-B-C32.

\section{AUTHOR CONTRIBUTIONS}

Conceptualization, Manuel Bolaños, César Collazos and Francisco Gutiérrez; methodology, Manuel Bolaños, César Collazos and Francisco Gutiérrez; investigation, Manuel Bolaños, César Collazos and Francisco Gutiérrez; writing-original draft preparation, Manuel Bolaños; writing-review and editing, Manuel Bolaños, César Collazos and Francisco Gutiérrez; supervision, César Collazos and Francisco Gutiérrez. All authors have read and agreed to the published version of the manuscript.

\section{CONFLICTS OF INTEREST}

The authors declare that there is no conflict of interest. 


\section{REFERENCES}

[1] B. Klimova; P. Poulova, Older People and Technology Acceptance Blanka, in Human Aspects of IT for the Aged Population. Acceptance, Communication and Participation. ITAP 2018. Lecture Notes in Computer Science vol. 10926. Springer International Publishing, 2018. https://doi.org/10.1007/978-3-319-92034-4_7

[2] L. Shore; V. Power; A. de Eyto; L. W. O'Sullivan, "Technology acceptance and user-centred design of assistive exoskeletons for older adults: A commentary," Robotics, vol. 7, no. 1, pp. 1-13, Jan. 2018. https://doi.org/10.3390/robotics7010003

[3] United Nations, "Perspectivas de la Población Mundial 2019," New York, NY, USA, 2019. URL

[4] M. del C. Carbajo Vélez, "Mitos y estereotipos sobre la vejez. Propuesta de una concepción realista y tolerante," Rev. la Fac. Educ. Albacete, no. 24, pp. 87-96, 2009. URL

[5] R. Weintraub; J. Colucci, "Design Thinking Can Help Improve Care for the Elderly," Harverd Bus. Rev., 2015. URL

[6] M. Syeda; Y.-M. Kwon, "Photo Alive! Application and method for intergenerational social communication," in 2017 19th International Conference on Advanced Communication Technology (ICACT), Bongpyeong, 2017, pp. 326-332. https://doi.org/10.23919/ICACT.2017.7890108

[7] P. Guo, "Older adults learning computer programming: Motivations, frustrations, and design opportunities," Conf. Hum. Factors Comput. Syst. - Proc., vol. 2017, pp. 7070-7083, Denver Colorado USA, 2017. https://doi.org/10.1145/3025453.3025945

[8] F. Rodríguez; S. F. Ochoa; F. J. Gutierrez, "Seamlessly Mediation of Social Interaction Services Respecting Communication Preferences," Proceedings, vol. 2, no. 19, p. $1249,2018$. https://doi.org/10.3390/proceedings2191249

[9] M. Bolaños; C. Collazos; F. Gutiérrez, "Adapting a Virtual Assistant Device to Support the Interaction with Elderly People," Proceedings of the 6th International Conference on Information and Communication Technologies for Ageing Well and e-Health, pp. 291-298, 2020. https://doi.org/10.5220/0009840102910298

[10] M. McLaughlin, "What a Virtual Assistant is and How it Works.”Jan 2020. URL

[11] A. Reis; P. Dennis; H. Paredes; J. Barroso, "Using Intelligent Personal Assistants to Strengthen the Elderlies' Social Bonds," 11th Int. Conf. UAHCI 2017, vol. 10279, pp. 612-620, New York, 2017. https://doi.org/10.1007/978-3-319-58700-4 48

[12] J. F. Bravo-Torres; J. O. Ordoñez-Ordoñez; P. L. Gallegos-Segovia; P. E. Vintimilla-Tapia; M. López-Nores; Y. Blanco-Fernández, "A context-aware platform for comprehensive care of elderly people: Proposed architecture," 2017 Chil. Conf. Electr. Electron. Eng. Inf. Commun. Technol. CHILECON 2017, pp. 1-6, Pucon, 2017. https://doi.org/10.1109/CHILECON.2017.8229507

[13] J. O. Ordoñez-Ordoñez; J. F. Bravo-Torres; O. D. Sari-Villa; E. F. Ordoñez-Morales; M. López-Nores; Y. Blanco-Fernández, "Stimulating social interaction among elderly people through sporadic social networks," 2017 Int. Caribb. Conf. Devices, Circuits Syst. ICCDCS, pp. 97-100, Cozumel. 2017. https://doi.org/10.1109/ICCDCS.2017.7959698

[14] A. Yurkewich; A. Stern; R. Alam; R. Baecker, "A field study of older adults with cognitive impairment using tablets for communication at home: Closing technology adoption gaps using InTouch," Int. J. Mob. Hum. Comput. Interact., vol. 10, no. 2, pp. 1-30, Apr. 2018. https://doi.org/10.4018/IJMHCI.2018040101

[15] S. Arlati et al., "A social virtual reality-based application for the physical and cognitive training of the elderly at home,” Sensors, vol. 19, no. 2, pp. 1-17,Jan. 2019. https://doi.org/10.3390/s19020261

[16] G. Kouroupetroglou; A. Pino; P. Riga, "A methodological approach for designing and developing web-based inventories of mobile Assistive Technology applications," Multimed. Tools Appl., vol. 76, no. 4, pp. 53475366, Feb. 2017. https://doi.org/10.1007/s11042-016-3822-3

[17] F. D. Davis, "Perceived usefulness, perceived ease of use, and user acceptance of information technology," MIS Q. Manag. vol. 13, no. 3, pp. 319-339, Sep. 1989. https://doi.org/10.2307/249008

[18] II-Yeol Song et al., Advances in Conceptual Modeling - Challenges and Opportunities, vol. 5232, Springer, Oct. 2008.

[19] J. Kitzinger, “Qualitative Research: Introducing focus groups,” BMJ, vol. 311, no. 7000, p. 299 , Jul. 1995. https://doi.org/10.1136/bmj.311.7000.299

[20] G. Cafagna; N. Aranco; P. Ibarrarán; M. L. Oliveri; N. Medellín;; M. Stampini, "Envejecer con cuidado: Atención a la dependencia en América Latina y el Caribe," Banco Interam. Desarro., Oct. 2019. http://dx.doi.org/10.18235/0001972

[21] N. Aranco; P. Ibarrarán; N. Medellín; M. Stampini, "Panorama de envejecimiento y dependencia en América Latina y el Caribe I Publications," Banco Interam. Desarro., 2018. URL

[22] C. A. Collazos; L. A. Guerrero; J. A. Pino; S. F. Ochoa, "Collaborative scenarios to promote positive interdependence among group members," Design, Implementation, and Use. CRIWG 2003. Lecture Notes in Computer Science, vol 2806. Springer, Berlin, 2003. https://doi.org/10.1007/978-3-540-39850-9_30 
[23] O. A. Testa; E. R. C. Fonseca; G. Montejano; O. Dieste, "Coordination of Ubiquitous Devices in Pervasive Environments: A Proposal Based on WS-CDL," Proc. - 38 th Int. Conf. Chil. Comput. Sci. Soc. SCCC, Concepcion, 2019. pp. 1-8. https://doi.org/10.1109/SCCC49216.2019.8966390

[24] Departamento Administrativo Nacional de Estadística - DANE, “Cuántos somos?” 2019. URL

[25] Departamento Administrativo Nacional de Estadística - DANE, "Soledad' en colombia, una aproximación desde las fuentes de estadísticas oficiales," Ser. Notas Estadisticas, 2020. URL 